OPEN ACCESS

Edited by:

Hong Zhu,

Zhejiang University, China

Reviewed by:

Yuan Tang,

University of Toledo, United States

Bakul Dhagat-Mehta,

University of Missouri, United States

*Correspondence:

Defang Li

lidefang@163.com

Qiusheng Zheng

zqsyt@sohu.com

tThese authors have contributed equally to this work

Specialty section:

This article was submitted to Pharmacology of Anti-Cancer Drugs,

a section of the journal

Frontiers in Oncology

Received: 02 May 2020 Accepted: 27 August 2020

Published: 16 October 2020

Citation:

Hu X, Yang Z, Liu W, Pan Z, Zhang X, Li M, Liu X, Zheng Q and Li D (2020)

The Anti-tumor Effects of $p$-Coumaric Acid on Melanoma A375 and B16 Cells. Front. Oncol. 10:558414. doi: $10.3389 /$ fonc. 2020.558414

\section{The Anti-tumor Effects of p-Coumaric Acid on Melanoma A375 and B16 Cells}

\author{
Xue $\mathrm{Hu}^{1+}$, Zihui Yang ${ }^{1+}$, Wenjing Liu ${ }^{1+}$, Zhaohai Pan ${ }^{1}$, Xin Zhang ${ }^{1}$, Minjing Li $^{1}$, Xiaona Liu ${ }^{1}$, \\ Qiusheng Zheng ${ }^{1,2 *}$ and Defang $\mathrm{Li}^{1 *}$
}

${ }^{1}$ Yantai Key Laboratory of Pharmacology of Traditional Chinese Medicine in Tumor Metabolism, School of Integrated Traditional Chinese and Western Medicine, Binzhou Medical University, Yantai, China, ${ }^{2}$ Key Laboratory of Xinjiang Endemic

Phytomedicine Resources of Ministry of Education, School of Pharmacy, Shihezi University, Shihezi, China

Background: Existing research shows that $p$-coumaric acid ( $p-C A)$ can inhibit the proliferation of a variety of tumor cells in vitro. However, there are no reports on the anti-tumor effects of $p$-CA on melanoma cells. In this study, the inhibitory effects of $p$-CA on mouse melanoma B16 and human melanoma $\mathrm{A} 375$ cells are reported, and the related mechanisms are investigated.

Methods: CCK-8 assay was used to detect the effects of $p$-CA on cell vitality, colony formation assay was used to observe the effects on cell proliferation, Hoechst 33,258 staining was used to observe the morphology of apoptotic cells, flow cytometry was used to detect the effects on apoptosis and the cell cycle, and western blot was used to measure the levels of cell cycle- and apoptosis-related signaling pathway proteins.

Results: $p$-CA significantly inhibits cell proliferation of A375 and B16 cells in a dose-dependent manner and obviously induced cell morphological changes. $p$-CA arrested A375 cells in the S phase by downregulating the cell cycle-related proteins Cyclin $A$ and CDK2, and arrested B16 cells in the G0-G1 phase through downregulating the cell cycle-related proteins Cyclin E and CDK2. In addition, $p$-CA significantly promoted apoptosis of A375 and B16 cells. Furthermore, $p$-CA significantly upregulated the levels of Apaf1 and Bax and downregulated the levels of $\mathrm{Bcl}-2$, and subsequently increased the levels of cytoplasmic cytochrome c (Cyto-c), cleaved caspase-3, and cleaved caspase-9, leading to apoptosis in A375 and B16 cells.

Conclusion: $p$-CA can significantly inhibit the proliferation of human and mouse melanoma cells in vitro. Our research is a step in the development of anti-melanoma drugs.

Keywords: $p$-coumaric acid ( $p$-CA), melanoma, B16 cells, A375 cells, apoptosis, cell cycle arrest

\section{INTRODUCTION}

Malignant melanoma (MM) is a malignant tumor of melanocytes originating from the neural crest, which has a high degree of malignancy, easily spreads, and has a poor prognosis. It is one of the most common tumors in the world, and in recent years, its incidence has increased each year. Melanoma is most common in Caucasian people, but its 
incidence has increased in recent years among Asians. In addition, unlike other solid tumors, melanoma mainly affects young and middle-aged people (the median age at the time of diagnosis is 57); the incidence increases linearly between the ages of 25 and 50 and then decreases (1). Therefore, melanoma is a big threat that seriously affects the quality of human life.

The most common treatment for melanoma is surgical resection. Unfortunately, this treatment can only be given in the early stage of local malignancy. The metastatic stage of malignant melanoma still presents huge treatment challenges (2). At present, targeted therapy and immunotherapy are the main treatments for metastatic melanoma, and they have become the focus of clinical research. Although some positive results have been achieved for targeted therapy and immunotherapy at this stage, these treatment methods can only be applied in a narrow population, are expensive, and require a high medical level, and can therefore not be widely used in clinical practice.

$p$-Coumaric acid ( $p$-CA), also known as 4-hydroxycinamic acid, has a molecular formula of $\mathrm{C}_{9} \mathrm{H}_{8} \mathrm{O}_{3}$. $p$-CA is a phenolic acid that is non-toxic to mice $\left(\mathrm{LD}_{50}=2,850 \mathrm{mg} \cdot \mathrm{kg}^{-1}\right)$ (3). It is widely found in mushrooms, grains (corn, rice, oats, and wheat), fruits (apples, pears, and grapes), and vegetables (carrots, potatoes, beans, onions, and tomatoes) (4) and has anti-inflammatory (5), antioxidant (4), anti-diabetic (6), anti-platelet aggregation (3), and anti-cancer (7) effects, among other biological functions. Recent studies have shown that $p$-CA has the ability to inhibit the proliferation and migration of tumor cells; for example, it can significantly inhibit the proliferation and migration of human lung cancer A549 cells and colon adenocarcinoma HT29-D4 cells in a dose-dependent manner (8). p-CA can also promote apoptosis of tumor cells; for example, $p$-CA inhibits the formation of polyps by improving the detoxification and apoptotic effects of 1,2-dimethylhydrazine on the rat colon (9).

Other pharmacological effects of $p$-CA include the inhibition of melanin production. Tyrosinase (TYP) is a key enzyme that catalyzes the production of melanin. The structure of $p$-CA is similar to that of tyrosine (TYP), and both compete for the active site on TYP (10). p-CA inhibits TYP activity, thereby inhibiting the formation of melanin in the cells.

In this study, we investigated the effects of $p$-CA on the proliferation of human melanoma A375 cells and mouse melanoma B16 cells. The results showed that $p$-CA can inhibit the proliferation of melanoma cells by causing cell cycle arrest and inducing apoptosis.

\section{RESULTS}

\section{p-CA Inhibits Proliferation and Colony Formation in A375 and B16 Cells}

First, we used the cell counting kit-8 (CCK-8) assay to examine the effects of $p$-CA on the cell proliferation capacity. We found that $p$-CA significantly inhibited the proliferation of A375 and B16 cells (Figures 1A,B). The $\mathrm{IC}_{50}$ value of $p$-CA on A375 cells for 24 -h treatment was $4.4 \mathrm{mM}$, and the $\mathrm{IC}_{50}$ value of p-CA for 48 -h treatment was $2.5 \mathrm{mM}$ (Figure 1A). Based on these $\mathrm{IC}_{50}$ values, we used $p$-CA concentrations of $1.5,2.5$, and $3.5 \mathrm{mM}$ in subsequent $\mathrm{A} 375$ cell experiments. The $\mathrm{IC}_{50}$ value of $p$-CA on $\mathrm{B} 16$ cells was $4.1 \mathrm{mM}$ for 24 -h treatment and $2.8 \mathrm{mM}$ for 48 -h treatment (Figure 1B), so we used $p$ CA concentrations of $2.0,3.0$, and $4.0 \mathrm{mM}$ in subsequent B16 cell experiments. At the same time, we used CCK-8 assay to examine the effect of $p$-CA on the proliferation of $\mathrm{HaCaT}$ cells. We found that $p$-CA significantly inhibited the proliferation of HaCaT cells at the concentration of $3.0-5.0 \mathrm{mM}$ after $24 \mathrm{~h}$ treatment, However, the cytotoxicity of $p$-CA to HaCaT cells was significantly lower than that to A375 cells (Figures 1C,D).

Second, we observed the morphological changes of cells after $48 \mathrm{~h}$ of treatment with different concentrations of $p$ CA under the microscope. We clearly observed that with increasing $p$-CA concentrations, compared with the control group, the number of A375 and B16 cells decreased, the morphology changed, intercellular contact disappeared, and more cells detached (Figure 1E). Simultaneously, the results of colony formation experiments showed that $p$-CA could inhibit the colony formation of A375 and B16 cells (Figure 1F).

\section{p-CA Causes A375 and B16 Cell Cycle Arrest}

We used flow cytometry to detect the cell cycle phases of A375 and B16 cells treated with different concentrations of $p$-CA for $24 \mathrm{~h}$. The PI single staining results showed that the proportion of A375 cells in the $S$ phase was significantly increased in the $p$-CA treatment groups (2.5 and $3.5 \mathrm{mM}$ ) (Figures $2 \mathrm{~A}, \mathbf{B}$ ), and the proportion of B16 cells in the G0-G1 phase was significantly increased in the $p$-CA treatment groups $(3.0$ and $4.0 \mathrm{mM})$ (Figures 2C,D).

\section{p-CA Regulates the Activity of Cyclin-CDK Complexes and Cell Cycle Progression}

To explore the mechanism by which $p$-CA changes the cell cycle, we performed western blot analysis to examine the levels of cell cycle-related proteins in p-CA-treated A375 and B16 cells. p-CA (2.5 and $3.5 \mathrm{mM})$ significantly reduced the expression levels of CDK2 and Cyclin A in A375 cells (Figures 3A,B) and the levels of CDK2 and Cyclin E in B16 cells (Figures 3C,D).

\section{p-CA Induces A375 and B16 Cell Apoptosis}

The effect of $p$-CA on A375 and B16 cell apoptosis was determined by Hoechst 33,258 staining. Under normal conditions, nuclei are round and pale blue, while the fluorescence intensity of the apoptotic nucleus is higher. Moreover, apoptotic cells are more condensed and have a disturbed mass-like morphology. Apoptosis also reduces the number of cells (Figures 4A,B). We also used flow cytometry to detect the proportion of apoptotic A375 and B16 cells after treatment with $p$-CA. The results showed that the number of apoptotic cells was significantly increased upon p-CA treatment in both A375 and B16 cells (Figures 4C-F). 

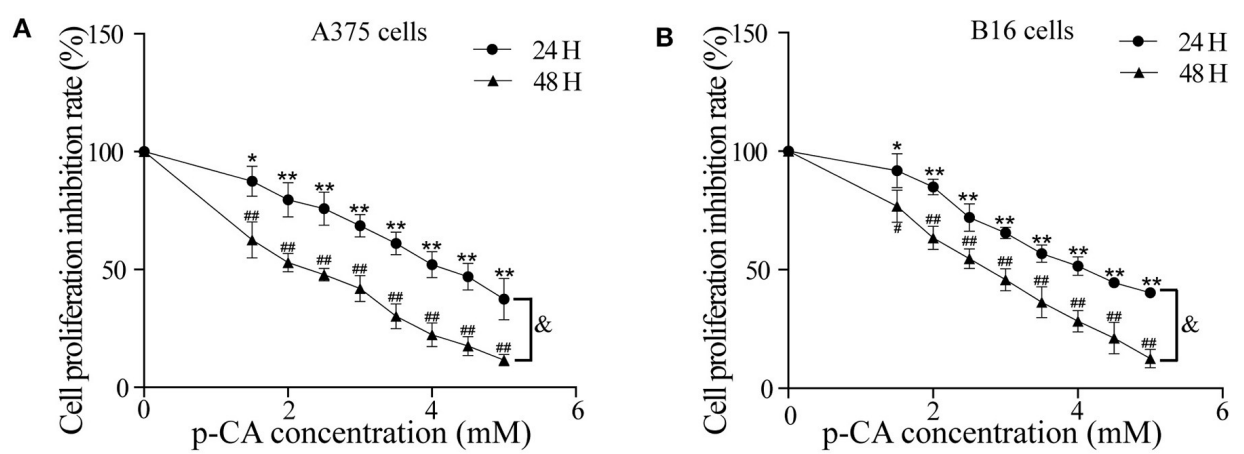
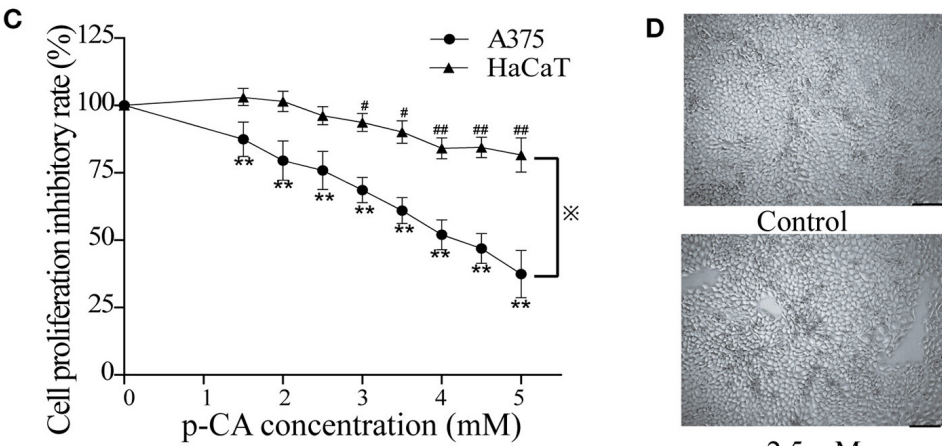

Control

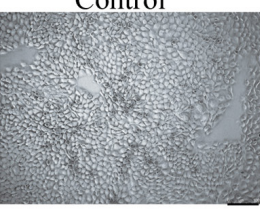

$2.5 \mathrm{mM}$

E

A375

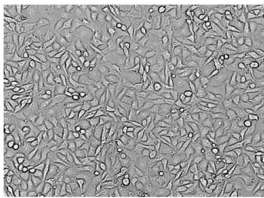

Control

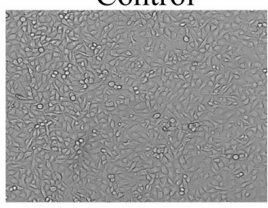

Control

F

A375

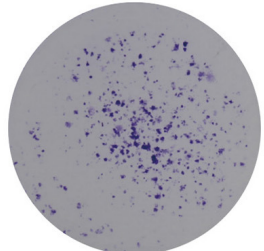

Control

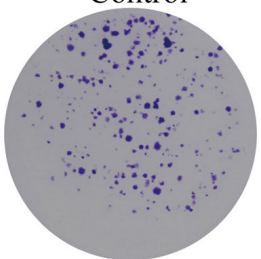

Control

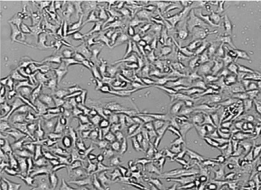

$1.5 \mathrm{mM}$

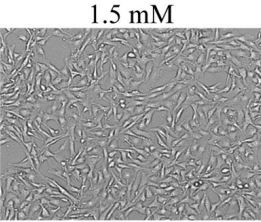

$2.0 \mathrm{mM}$

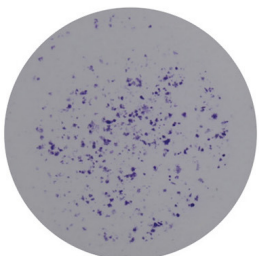

$1.5 \mathrm{mM}$

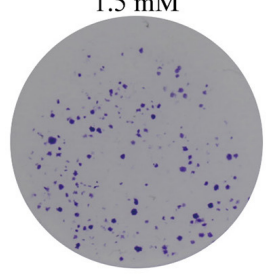

$2.0 \mathrm{mM}$

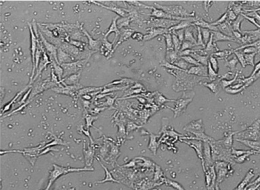

$2.5 \mathrm{mM}$

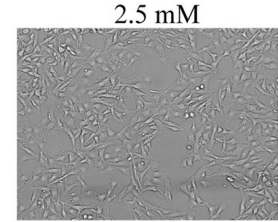

$3.0 \mathrm{mM}$

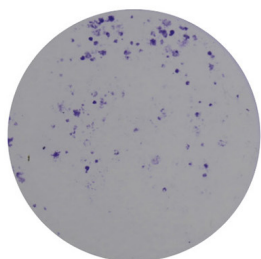

$2.5 \mathrm{mM}$

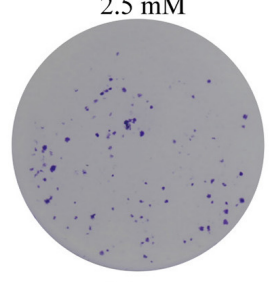

$3.0 \mathrm{mM}$

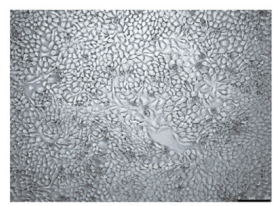

$1.5 \mathrm{mM}$

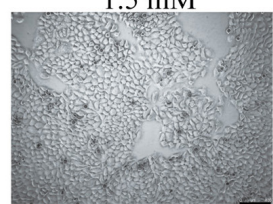

$3.5 \mathrm{mM}$
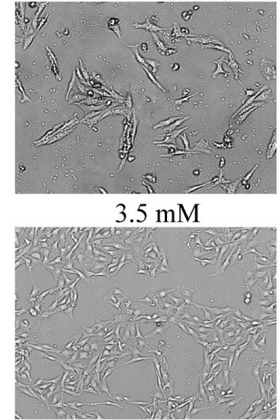

$4.0 \mathrm{mM}$

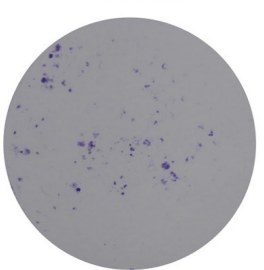

$3.5 \mathrm{mM}$

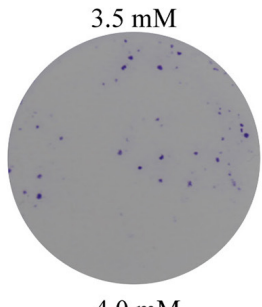

FIGURE 1 | p-CA inhibits proliferation and colony formation of A375 and B16 cells. (A,B) A375 and B16 cells were treated with p-CA. After incubation for 24 or $48 \mathrm{~h}$, the proliferation rates of A375 and B16 cells were measured by CCK-8 assay. (C) HaCaT, A375 and B16 cells were treated with p-CA. After incubation for $24 \mathrm{~h}$, the proliferation rates of HaCaT, A375 and B16 cells were measured by CCK-8 assay. (D) Morphological changes of p-CA-treated HaCaT cells were observed under a phase contrast microscope. (E) Morphological changes of A375 and B16 cells were observed under a phase contrast microscope. Scale bar, $50 \mu \mathrm{m}$. (F) The cell colonies were stained with crystal violet and observed under an inverted microscope. All data are expressed as the mean \pm SD of three independent experiments. ${ }^{\&} P<0.05$ compared with the A375 or B16 cells after $p$-CA treatment for $24 \mathrm{~h} .{ }^{\star} P<0.05$, ${ }^{\star \star} P<0.01,{ }^{\#} P<0.05$, $\# \# P<0.01$ compared with the control. 


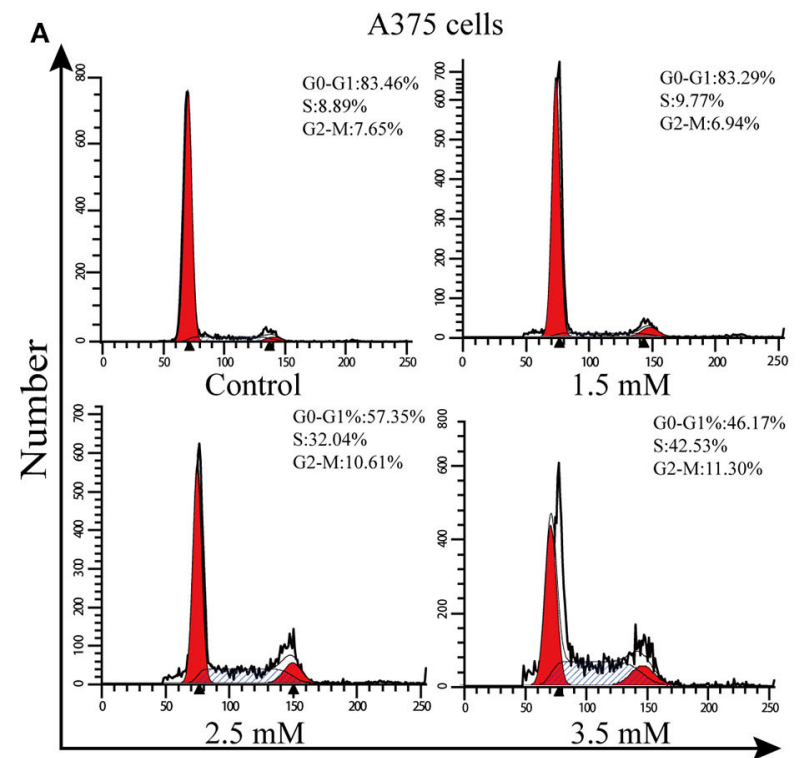

Propidium Iodide Fluorescence

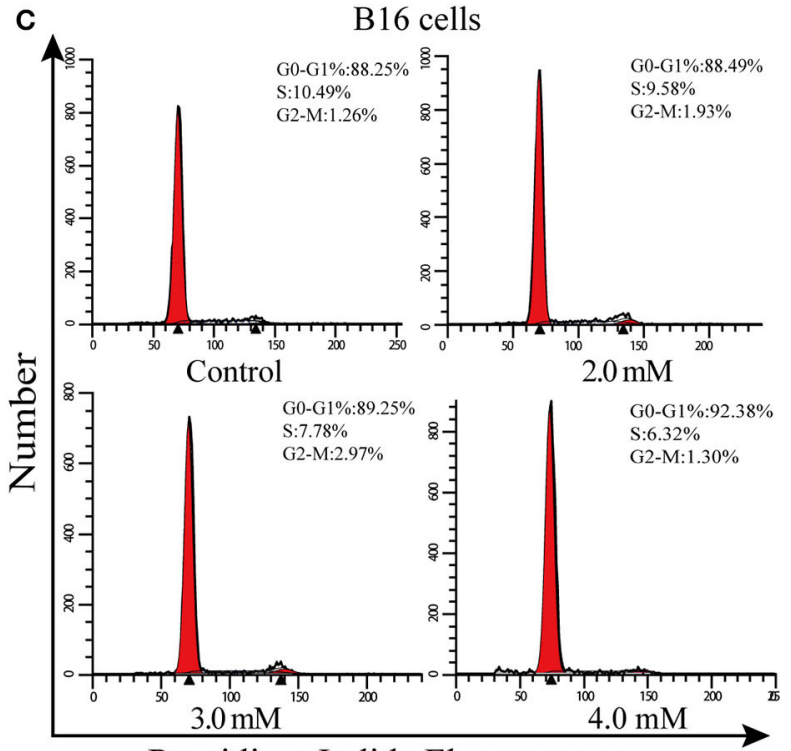

Propidium Iodide Fluorescence
B

A375 cells
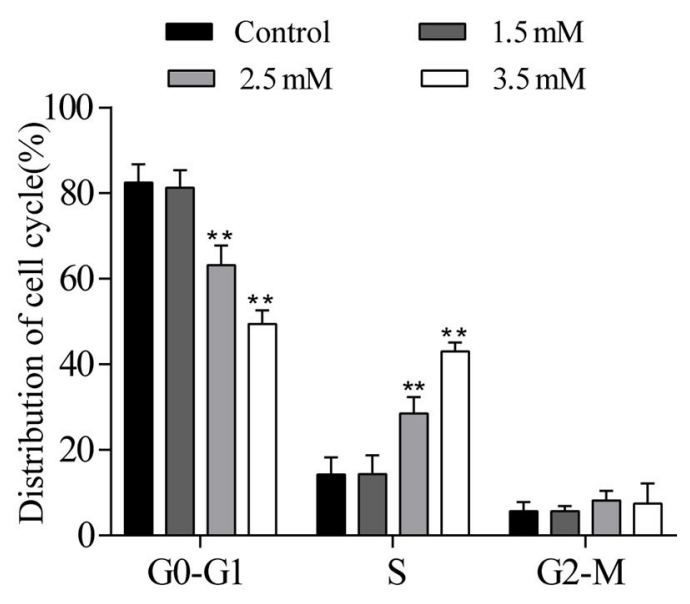

B16 cells

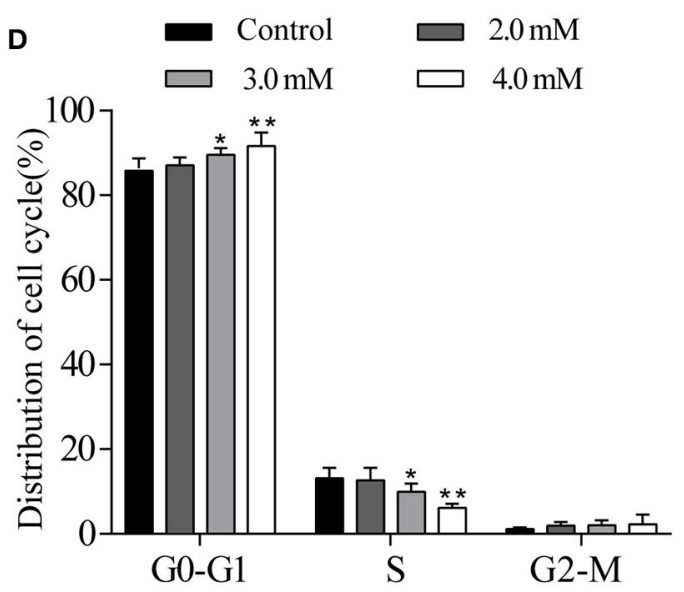

FIGURE 2 | p-CA causes A375 and B16 cell cycle arrest. (A) The cell cycle distribution of A375 cells treated with p-CA was measured by flow cytometry. (B) Statistical analysis of the cell cycle distribution of A375 cells treated with p-CA. (C) The cell cycle distribution of B16 cells treated with $p$-CA was measured by flow cytometry. (D) Statistical analysis of the cell cycle distribution of B16 cells treated with $p$-CA. All data are expressed as the mean \pm SD of three independent experiments. ${ }^{*} P<0.05,{ }^{*} P<0.01$ compared with the control.

\section{Effect of $p$-CA on Apoptosis-Related Proteins}

To explore the mechanism of apoptosis, we performed western blot analysis to examine the levels of apoptosis-related proteins in A375 and B16 cells treated with $p$-CA for $24 \mathrm{~h}$. The results showed that the levels of caspase- 3 and caspase- 9 decreased, and the levels of cleaved caspase- 3 and cleaved caspase- 9 increased in $p$-CAtreated A375 cells (2.5 and $3.5 \mathrm{mM}$ ) (Figures 5A,B) and B16 cells
(3.0 and $4.0 \mathrm{mM}$ ) (Figures 5C,D). These results indicate that $p$ $\mathrm{CA}$ induces apoptosis in A375 and B16 cells through regulating the caspase family.

\section{p-CA Induces A375 and B16 Cell Apoptosis Through the Bcl-2/Bax Signaling Pathway}

To further explore the underlying mechanisms, we examined the upstream regulatory factors of caspase- 3 and caspase- 9 

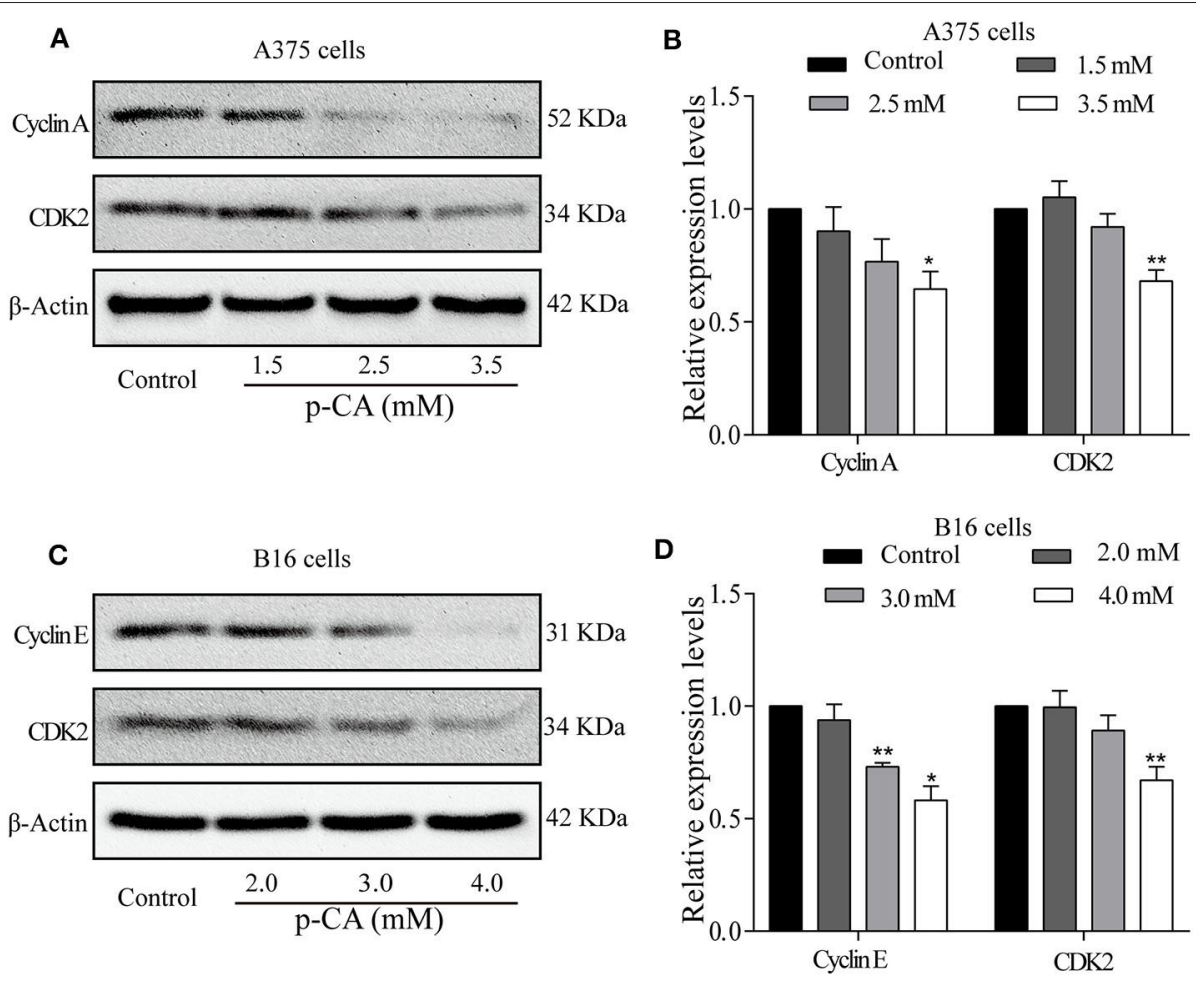

FIGURE 3 | p-CA regulates the activity of Cyclin-CDK complexes and cell cycle progression. (A) The protein levels of Cyclin A and CDK2 in A375 cells treated with $p$-CA, as measured by western blot. (B) Statistical analysis of Cyclin A and CDK2 levels in A375 cells. The ratio of protein levels was standardized according to the value of the control. (C) The protein levels of Cyclin E and CDK2 in B16 cells treated with p-CA, as measured by western blot. (D) Statistical analysis of Cyclin E and CDK2 levels in B16 cells. The ratio of protein levels was standardized according to the value of the control. All data are expressed as the mean \pm SD of three independent experiments. ${ }^{\star} P<0.05,{ }^{\star \star} P<0.01$ compared with the control.

in A375 and B16 cells after treatment with p-CA for $24 \mathrm{~h}$. The results showed that $p$-CA could downregulate Bcl-2 and upregulate Bax, Apaf1, and cytoplasmic Cyto-C levels in A375 cells (Figures 6A,B) and B16 cells (Figures 6C,D).

\section{DISCUSSION}

$p$-CA is a phenolic acid that is widely present in fruits, vegetables, and Chinese herbal medicines (11). It has anti-inflammatory, antioxidant, anti-diabetic, anti-platelet aggregation, and anticancer effects. Therefore, it has the potential to be developed as an anti-tumor drug, but there have been few reports on the subject. By CCK-8 assay and colony formation experiments, we found that $p$-CA has an inhibitory effect on the proliferation of melanoma cells. According to our flow cytometry results, $p$ CA can not only promote apoptosis of melanoma cells but also change the cell cycle process. We also found the $p$-CA-induced changes in the levels of cell cycle-related and apoptosis-related proteins and upstream signaling pathway proteins.

Numerous studies have shown that tumorigenesis and cancer development are related to the disruption of the cell cycle. The cell cycle duration of tumor cells is almost the same as that of normal cells, but the proportion of actively dividing cells in tumor tissues is much higher than in normal tissues (11). The cell cycle is the entire process of cell division, which is divided into two stages: the interphase and the mitotic phase. The interphase is divided into the G1, S, and G2 phases. Cells in the G1 phase rapidly synthesize RNA and proteins, preparing materials and energy for DNA replication in the S phase. Cells in the S phase are characterized by DNA replication, doubling the DNA content. The transition from the G1 phase to the $S$ phase is a critical moment in the cell cycle. If the cell is disturbed by certain factors, this will affect the replication of DNA, which will cause mutations or terminate DNA replication. Cells in the G2 phase are prepared for the division phase. After the interphase, the cells enter the M phase for orderly cell division (12). The cell cycle is driven by the sequential activation by Cyclins of the corresponding Cyclin-dependent kinase (CDK). CDKs play a positive role in the regulation of cell cycle progression. Cyclin-dependent kinase inhibitors (CKIs) are negative cell cycle regulators. By directly binding to CDKs, CKIs can negatively regulate CDK activity (13). Different Cyclins can specifically regulate different cell cycle stages; for example, Cyclin E and CDK2 can form a Cyclin ECDK2 complex, allowing cells to enter the $S$ phase from the G1 phase, and guiding cells into the G2/M phase (14). Cyclin A binds to CDK2 and is activated during the G1-S transition, thereby regulating cell proliferation (15). The cell cycle is also monitored by the cell cycle checkpoint, which is a negative feedback regulatory mechanism (16). If DNA damage is detected 

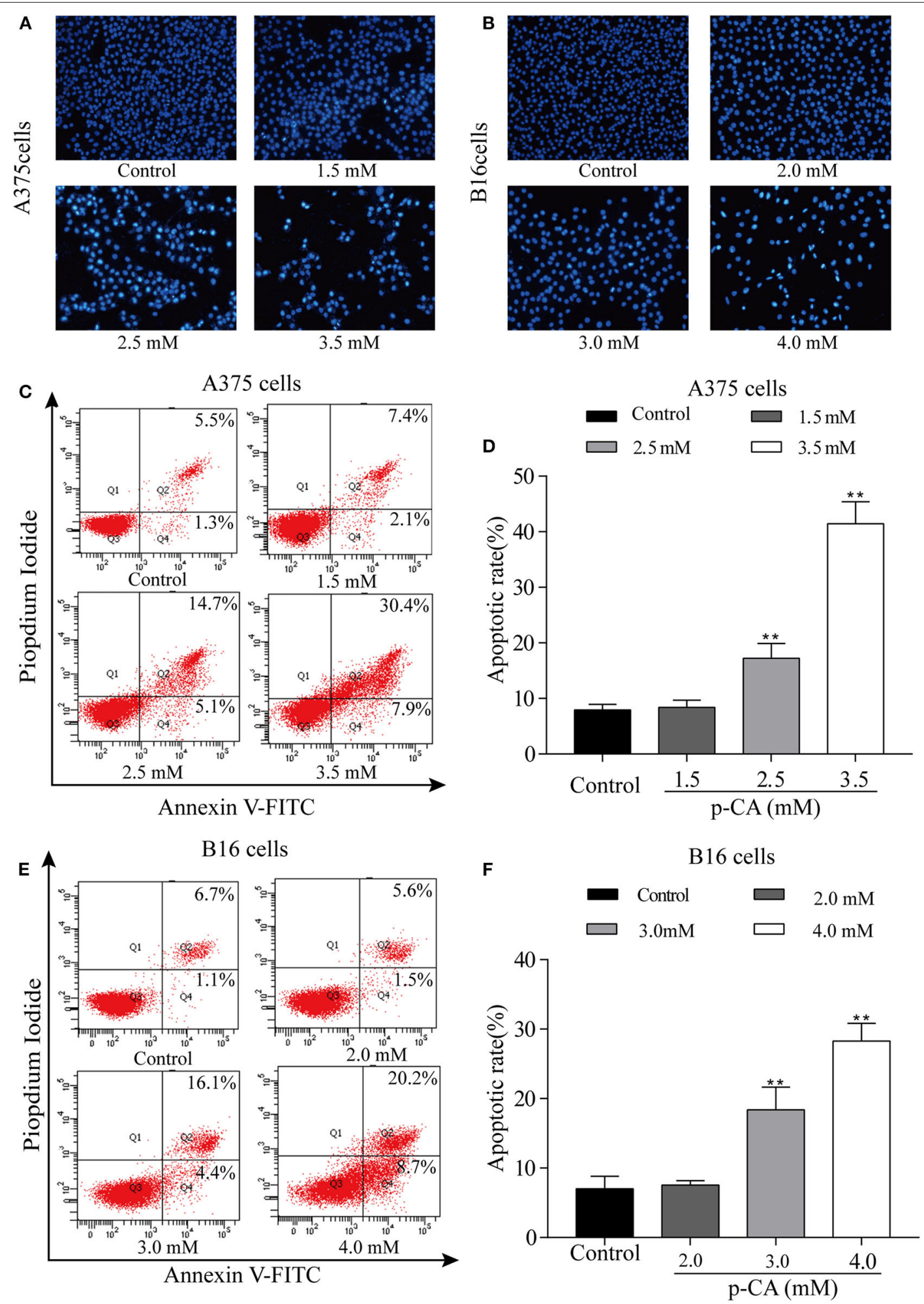

FIGURE $4 \mid p$-CA induces A375 and B16 cell apoptosis. (A,B) After Hoechst 33,258 staining, the nucleus of A375 and B16 cells treated with $p$-CA showed morphological changes typical of apoptosis. (C) The apoptosis rate of A375 cells treated with $p$-CA was measured by Annexin V-FITC/PI double staining. (D) Statistical analysis of the apoptosis rate of A375 cells treated with $p$-CA. (E) The apoptosis rate of B16 cells treated with $p$-CA was measured by Annexin V-FITC/PI double staining. (F) Statistical analysis of the apoptosis rate of B16 cells treated with $p$-CA. All data are expressed as the mean \pm SD of three independent experiments. ${ }^{* *} P<0.01$ compared with the control. 

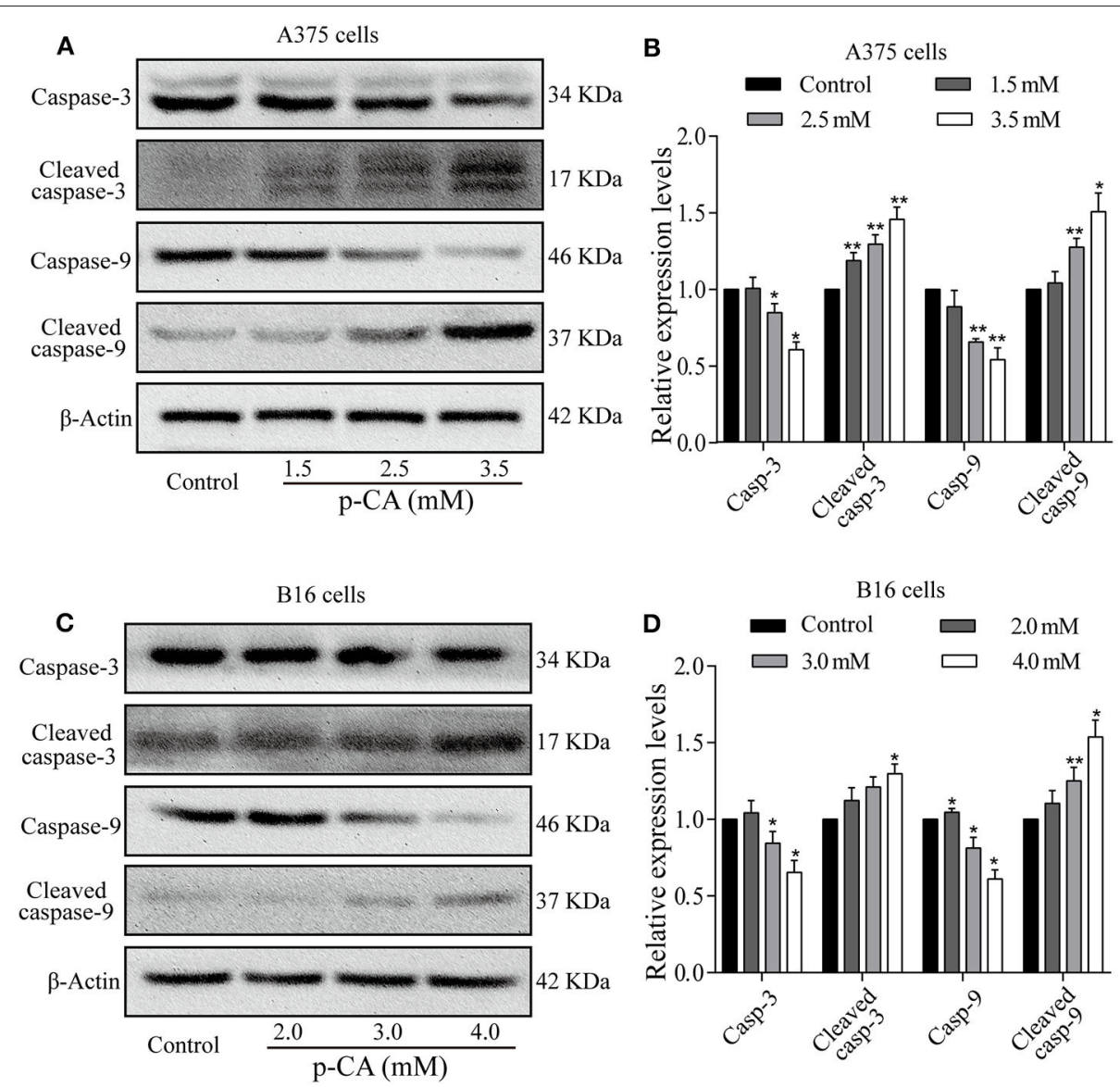

FIGURE 5 | Effects of $p$-CA on apoptosis-related proteins. (A) The protein levels of caspase-3/9 and cleaved caspase-3/9 in A375 cells treated with $p$-CA were measured by western blot. (B) The relative protein levels of caspase-3/9 and cleaved caspase-3/9 in A375 cells treated with $p$-CA were statistically analyzed. (C) The protein levels of caspase-3/9 and cleaved caspase-3/9 in B16 cells treated with $p$-CA were measured by western blot. (D) The relative protein levels of caspase-3/9 and cleaved caspase-3/9 in B16 cells treated with $p$-CA were statistically analyzed. The ratio of protein levels is normalized according to the value of the control group. All data are expressed as the mean $\pm \mathrm{SD}$ of three independent experiments. ${ }^{\star} P<0.05,{ }^{\star \star} P<0.01$ compared with the control.

during the cell cycle, the cell cycle checkpoint is activated, interrupting the cell cycle process (17). Western blot results from the present study showed that $p$-CA decreases the levels of the key proteins CDK2 and Cyclin A in the A375 cell cycle, thereby blocking the progression of cells from the $S$ to the G2 phase, increasing the proportion of $\mathrm{S}$ phase cells. In B16 cells, p-CA decreases the levels of the key proteins CDK2 and Cyclin E, causing cell cycle arrest in the G0-G1 phase. In general, $p$-CA can block proliferation of different tumor cells in different ways.

Inducing apoptosis is another effective means to inhibit tumor cell proliferation (11). Apoptosis is an orderly form of cell death (18). Cells can autonomously enter apoptosis, which involves the activation, expression, and regulation of a series of genes. The caspase and Bcl-2 families are the main proteomes that induce apoptosis $(19,20)$. The caspase family is the protease family that performs apoptosis (21). The caspase family can be activated to degrade or inactivate some key cellular proteins, and its activation and regulation have important significance for the transmission of apoptotic signals (22). It is believed that procaspase can be activated by three methods: self-activation, trans-activation, and non-caspase protease activation. Caspase- 8 and caspase- 9 can be activated by self-cleavage by binding to each other (23). Once activated, the original caspase can activate other caspase zymogens, as occurs between caspase- 3 and caspase-9. In the present study, we found that $p$-CA leads to an increase in the levels of cleaved caspase- 3 and cleaved caspase-9, implying that $p$ CA could induce apoptosis via a caspase-dependent mechanism.

Bcl-2 and Bax belong to the Bcl-2 family. Bcl-2 inhibits apoptosis, and Bax promotes apoptosis. They play an important regulatory role in the process of apoptosis. Studies have shown that changes in the ratio of $\mathrm{Bcl}-2$ to Bax can regulate apoptosis. Bcl-2 overexpression has anti-apoptotic effects; in contrast, Bax overexpression stimulates apoptosis (24). In the present study, we found that Bcl-2 levels were significantly decreased and Bax levels were significantly increased in p-CA-treated A375 and B16 cells.

When cells undergo apoptosis, Bcl-2 controls mitochondrial outer membrane permeability by regulating the mitochondrial membrane potential (25). Bax, which is present in the cytoplasm, receives a signal from $\mathrm{Bcl}-2$ that allows $\mathrm{Bax}$ to relocate to the mitochondrial surface and to form a pore across the outer 

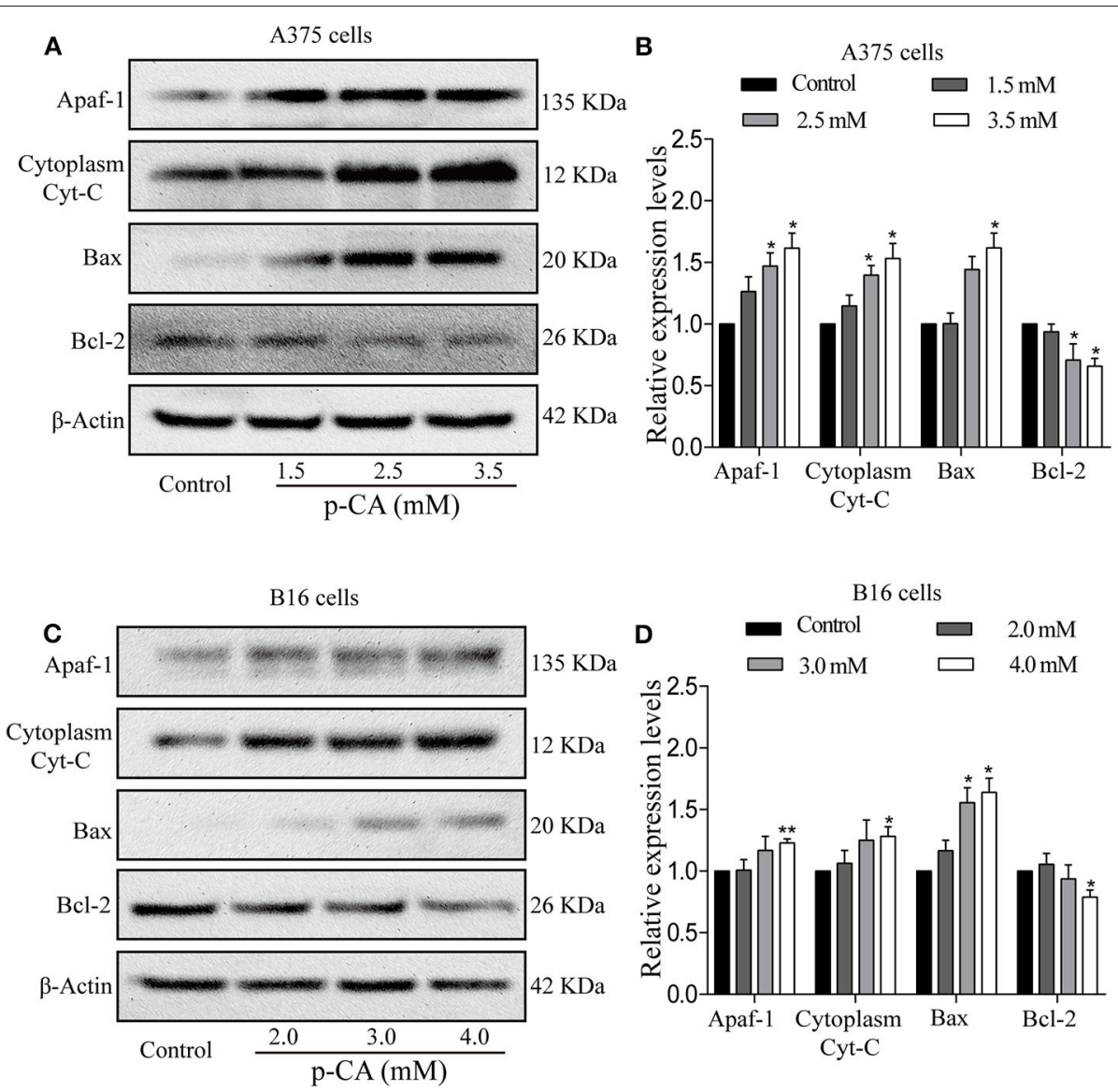

FIGURE 6 | p-CA induces A375 and B16 cell apoptosis through the Bcl-2/Bax signaling pathway. (A) The protein levels of Apaf1, cytoplasmic Cyto-C, Bax, and Bcl-2 in A375 cells treated with p-CA were measured by western blot. (B) Statistical analysis of the relative protein levels of Apaf1, cytoplasmic Cyto-C, Bax, and Bcl-2 in A375 cells treated with $p$-CA. The ratio of protein levels was normalized according to the value of the control. (C) The protein levels of Apaf1, cytoplasmic Cyto-C, $\mathrm{Bax}$, and Bcl-2 in B16 cells treated with $p$-CA were measured by western blot. (D) Statistical analysis of the relative protein levels of Apaf1, cytoplasmic Cyto-C, Bax, and $\mathrm{Bcl}-2$ in $\mathrm{B} 16$ cells treated with $p$-CA. The ratio of protein levels was normalized according to the value of the control. All data are expressed as the mean \pm SD of three independent experiments. ${ }^{*} P<0.05,{ }^{*} P<0.01$ compared with the corresponding control.

mitochondrial membrane, leading to increased mitochondrial membrane permeability. Pro-apoptotic substances such as Cyto-C are released from the outer and inner membranes of mitochondria into the cytoplasm. Cytoplasmic Cyto-C interacts with Apaf1 and activates caspase-9, and activated caspase- 9 can activate other caspases, such as caspase- 3 and caspase-7, thereby starting the caspase cascade and causing apoptosis (25). Bal-2 levels were significantly decreased and cytoplasmic Cyto-C and Apaf1 levels were remarkably increased in p-CA-treated A375 and $\mathrm{B} 16$ cells, implying that $p$-CA could induce apoptosis in A375 and B16 cells through the mitochondrial-mediated apoptotic signaling pathway, which is regulated by the Bcl-2 family.

However, some limitations in our study should be noted. The anti-tumor effects of $p$-coumaric acid wasn't examined in a melanoma-xenografted model in nude mice. In conclusion, our results showed that $p$-CA inhibits cell proliferation in B16 and A375 cells and induces apoptosis via a mitochondrialmediated signaling pathway. This study provides evidence for the development of $p$-CA as an anti-melanoma drug.

\section{MATERIALS AND METHODS}

\section{Cell Lines and Cell Culture}

Mouse melanoma B16 cells (Cat. No. TCM 2) and human melanoma A375 cells (Cat. No. SCSP-533) from the Cell Bank of Type Culture Collection of Chinese Academy of Sciences China (Shanghai, China) were cultured in a sterile cell culture chamber (HF240, HEALFORCE, Shanghai Lishen Scientific Equipment Co. Ltd.) at $37^{\circ} \mathrm{C}$ with $95 \%$ air and $5 \% \mathrm{CO}_{2}$ with saturated humidity. B16 cells were cultured in 1,640 medium (Cat. No. SH30809.01, Hyclone) supplemented with 10\% FBS (Cat. No. 10091-148, Gibco) and 1\% streptomycin solution (Cat. No. P1400, Solarbio). A375 cells were cultured in DMEM high glucose medium (Cat. No. SH30022.01, Hyclone) supplemented with $10 \%$ FBS, $1 \%$ streptomycin solution, and $1 \%$ sodium pyruvate (Cat. No. SP0100, Solarbio). Similarly, the normal human keratinocyte cell line HaCaT cells (Cat. No. KG300, KeyGEN BioTECH) were cultured in a DMEM high glucose medium supplemented with 10\% FBS and 1\% streptomycin solutions. 


\section{CCK-8 Assay}

Well-grown A375 cells, B16 cells and HaCaT cells were digested with $0.25 \%$ trypsin and collected by centrifugation at $800 \times g$ for $3 \mathrm{~min}$. Cells $(100 \mu \mathrm{l})$ were plated in a 96 -well plate $(8 \times$ $10^{3}$ cells/well). The cells were cultured for $24 \mathrm{~h}$, and the medium was replaced with $200 \mu \mathrm{l}$ complete medium containing $p$-CA $(1.5,2,2.5,3,3.5,4,4.5$, and $5 \mathrm{mM})$. The complete medium containing $1 \%$ DMSO was used as the control group. Cells were incubated for an additional 24 or $48 \mathrm{~h}$, and $10 \mu \mathrm{l} \mathrm{CCK}-8$ solution (Cat. No. CK04, Dojindo) was added to each well for $2 \mathrm{~h}$. Finally, the absorbance of each well at $450 \mathrm{~nm}$ was measured by a multi-plate reader (Infinite200PRO, Tecan, Tecan Austria $\mathrm{GmbH}$, Grödig, Austria).

\section{Colony Formation Assay}

A375 and B16 cells were centrifuged at $800 \times g$ for $3 \mathrm{~min}$. Cells $(3 \mathrm{ml})$ were plated in a 6 -well plate $(250$ cells/well $)$. The cells were cultured for 1 day, and the medium was replaced with $3 \mathrm{ml}$ complete medium containing $p$-CA $(1.5,2.5$, and $3.5 \mathrm{mM}$ for A375 cells; 2.0, 3.0, and $4.0 \mathrm{mM}$ for B16 cells). Cells were incubated for $48 \mathrm{~h}$, and the medium was refreshed. After 14 days, the culture medium was discarded, and the cells were washed twice with PBS. Cells were fixed with $4 \%$ paraformaldehyde for $15 \mathrm{~min}$, stained with $1 \%$ crystal violet (Cat. no. G1062, Solarbio) for $10 \mathrm{~min}$, washed three times with PBS (until the liquid was clear), and dried at room temperature. Images were taken to observe the colony formation.

\section{Hoechst 33,258 Staining}

The cells were digested with $0.25 \%$ trypsin and centrifuged at $800 \times g$ for $3 \mathrm{~min}$. Cells $(2 \mathrm{ml})$ were plated in a 6 -well plate $\left(3 \times 10^{5}\right.$ cells/well). The cells were cultured for $24 \mathrm{~h}$, and the medium was replaced with $3 \mathrm{ml}$ complete medium containing p-CA $(1.5,2.5$, and $3.5 \mathrm{mM}$ for A375 cells; 2.0, 3.0, and $4.0 \mathrm{mM}$ for B16 cells). Cells were incubated for $48 \mathrm{~h}$ and washed twice with PBS. Fixation solution $(500 \mu \mathrm{l}$ of methanol:acetic acid $=$ 3:1) was added to each well for $10 \mathrm{~min}$. Cells were washed twice with PBS, and Hoechst 33,258 staining solution $(0.5 \mathrm{ml})$ was added to each well for $5 \mathrm{~min}$. Cells were washed three times with PBS. Nuclear morphology was observed under an inverted fluorescence microscope.

\section{Annexin V-FITC/PI Flow Cytometry for Apoptosis Detection}

Cells were digested with $0.25 \%$ trypsin and centrifuged at 800 $\times g$ for $3 \mathrm{~min}$. Cells $(4 \mathrm{ml})$ were inoculated in a petri dish $(6$ $\times 10^{5}$ cells/plate). The cells were cultured for $24 \mathrm{~h}$, and the medium was replaced with $3 \mathrm{ml}$ complete medium containing p-CA $(1.5,2.5$, and $3.5 \mathrm{mM}$ for A375 cells; 2.0, 3.0, and $4.0 \mathrm{mM}$ for B16 cells). The cells were incubated for $48 \mathrm{~h}$, trypsinized, and centrifuged at $2,000 \times g$ for $3 \mathrm{~min}$ at $4^{\circ} \mathrm{C}$. The cells were resuspended in pre-cooled $\mathrm{PBS}$ and centrifuged again at 2,000 $\times g$ for $3 \mathrm{~min}$ at $4{ }^{\circ} \mathrm{C}$. Annexin V-FITC and PI were added, the solutions were mixed well, and the samples were incubated for $10 \mathrm{~min}$ in the dark at $4^{\circ} \mathrm{C}$. Cell fluorescence was detected by flow cytometry.

\section{Cell Cycle Detection}

The cells were inoculated in a 6-well plate at a suitable concentration and cultured in a $5 \% \mathrm{CO}_{2}$ incubator at $37^{\circ} \mathrm{C}$ for $24 \mathrm{~h}$. The medium was replaced with complete medium containing $p$-CA $(1.5,2.5$, and $3.5 \mathrm{mM}$ for A375 cells; 2.0, 3.0, and $4.0 \mathrm{mM}$ for B16 cells), and the cells were incubated for $48 \mathrm{~h}$. The cells were digested with $0.25 \%$ trypsin, centrifuged at $800 \times g$ for $3 \mathrm{~min}$ at $4^{\circ} \mathrm{C}$, resuspended in PBS, and centrifuged again. The cell pellet was resuspended in fixation solution $(70 \%$ pre-cooled ethanol) and incubated at $4{ }^{\circ} \mathrm{C}$ overnight. The cells were centrifuged, RNase A solution was added to the cells, and cells were resuspended and incubated in a water bath at $37^{\circ} \mathrm{C}$ for $30 \mathrm{~min}$. PI staining solution was added at $4^{\circ} \mathrm{C}$ for $30 \mathrm{~min}$, and the cell cycle distribution was analyzed by flow cytometry.

\section{Western Blot Analysis}

Cells were treated with $p$-CA $(1.5,2.5$, and $3.5 \mathrm{mM}$ for A375 cells; 2.0, 3.0, and $4.0 \mathrm{mM}$ for B16 cells) for $24 \mathrm{~h}$. The cells were collected in lysis buffer and incubated on ice for $30 \mathrm{~min}$. The cells were mixed every $10 \mathrm{~min}$. The cells were centrifuged at $12,000 \times g$ at $4^{\circ} \mathrm{C}$ for $10 \mathrm{~min}$. The supernatant was collected, and the protein concentration was determined. Equal amounts of protein $(40 \mu \mathrm{g} / \mathrm{slot})$ were subjected to $10-12 \%$ SDS-PAGE. Proteins were transferred to a PVDF membrane, which was incubated with $5 \%$ milk blocking solution for $2 \mathrm{~h}$, followed by incubation with the following primary antibodies (all from Abcam, Cambridge, UK): antiCyclin A (1:1,000, ab53699), anti-Cyclin-dependent kinase 2 (CDK2, 1:1,000, ab32147), anti-Cyclin E (1:1,000, ab133266), anti-Bcl-2-associated X (BAX, 1:1,000, ab32503), anti-B-cell lymphoma-2 (Bcl-2, 1:1,000, ab32124), anti-cytochrome C (Cyto-C, 1:1,000, ab13575), anti-apoptotic protease activating factor-1 (Apaf1, 1:1,000, ab2000), anti-cleaved caspase-3 (1:1,000, ab32042), anti-caspase-3, (1:1,000, ab13585), anticleaved caspase- 9 (1:1,000, ab2324), and anti-caspase- 9 (1:1,000, ab202068). Subsequently, the membranes were washed with TBST buffer for $45 \mathrm{~min}$ and then probed with appropriate horseradish peroxidase-conjugated secondary antibodies for $1 \mathrm{~h}$. Immunoreactive bands were visualized by the Novex ${ }^{\mathrm{TM}}$ ECL Chemiluminescent Substrate Reagent Kit (WP20005; Thermo Fisher Scientific, Shanghai, China) using a film processor (BioSpectrum Imaging System, Upland, CA, USA). The grayscale value of each band was calculated by Image Pro Plus 6.0 (IPP6) software.

\section{Statistical Analysis}

All experiments were conducted at least three times. All data are shown as the mean \pm standard deviation (SD). The Student $t$-test, one-way analysis of variance (ANOVA), or two-way ANOVA was employed to analyze the statistical differences. The analyses were performed using SPSS 21.0 software (version 21.0, SPSS Inc., Chicago, IL, USA). $P<0.05$ were considered statistically significant. 


\section{DATA AVAILABILITY STATEMENT}

The raw data supporting the conclusions of this article will be made available by the authors, without undue reservation.

\section{AUTHOR CONTRIBUTIONS}

$\mathrm{XH}, \mathrm{ZY}, \mathrm{QZ}$, and DL designed the study. $\mathrm{XH}, \mathrm{ZY}$, and WL acquired the data and wrote the manuscript. $\mathrm{XH}, \mathrm{ZY}$, and $\mathrm{WL}$ collected cell samples for Hoechst 33,258 staining, cell cycle, and western blot analyses. ZP, XZ, ML, and XL interpreted and analyzed the data. QZ and DL revised and approved the final version of the manuscript. All authors contributed to the article and approved the submitted version.

\section{REFERENCES}

1. Leonardi GC, Falzone L, Salemi R, Zanghi A, Spandidos DA, Mccubrey JA, et al. Cutaneous melanoma: from pathogenesis to therapy (Review). Int $J$ Oncol. (2018) 52:1071-80. doi: 10.3892/ijo.2018.4287

2. Kwiatkowska D, Kluska P, Reich A. Beyond PD-1 immunotherapy in malignant melanoma. Dermatol Ther. (2019) 9:243-57. doi: 10.1007/s13555-019-0292-3

3. Pei KH, Ou JY, Huang JQ, Ou SY. p-Coumaric acid and its conjugates: dietary sources, pharmacokinetic properties and biological activities. J Sci Food Agric. (2016) 96:2952-62. doi: 10.1002/jsfa.7578

4. Shen Y, Song X, Li L, Sun J, Jaiswal Y, Huang J, et al. Protective effects of p-coumaric acid against oxidant and hyperlipidemia-an in vitro and in vivo evaluation. Biomed Pharmacother. (2019) 111:579-87. doi: 10.1016/j.biopha.2018.12.074

5. Sharma SH, Rajamanickam V, Nagarajan S. Antiproliferative effect of p-Coumaric acid targets UPR activation by downregulating Grp78 in colon cancer. Chem Biol Interact. (2018) 291:16-28. doi: 10.1016/j.cbi.2018. 06.001

6. Amalan V, Vijayakumar N, Indumathi D, Ramakrishnan A. Antidiabetic and antihyperlipidemic activity of p-coumaric acid in diabetic rats, role of pancreatic GLUT 2: In vivo approach. Biomed Pharmacother. (2016) 84:230-6. doi: 10.1016/j.biopha.2016.09.039

7. Jaganathan SK, Supriyanto E, Mandal M. Events associated with apoptotic effect of p-Coumaric acid in HCT-15 colon cancer cells. World J Gastroenterol. (2013) 19:7726-34. doi: 10.3748/wjg.v19.i43.7726

8. Nasr Bouzaiene N, Kilani Jaziri S, Kovacic H, Chekir-Ghedira L, Ghedira $\mathrm{K}$, Luis J. The effects of caffeic, coumaric and ferulic acids on proliferation, superoxide production, adhesion and migration of human tumor cells in vitro. Eur J Pharmacol. (2015) 766:99-105. doi: 10.1016/j.ejphar.2015. 09.044

9. Sharma SH, Rajamanickam V, Nagarajan S. Supplementation of p-coumaric acid exhibits chemopreventive effect via induction of Nrf2 in a short-term preclinical model of colon cancer. Eur J Cancer Prev. (2019) 28:472-82. doi: 10.1097/CEJ.0000000000000496

10. Arruda C, Ribeiro VP, Almeida MO, Mejia JAA, Casoti R, Bastos JK. Effect of light, oxygen and temperature on the stability of artepillin $\mathrm{C}$ and p-coumaric acid from Brazilian green propolis. J Pharm Biomed Anal. (2020) 178:112922. doi: 10.1016/j.jpba.2019.112922

11. Wang Y, Ji P, Liu J, Broaddus RR, Xue F, Zhang W. Centrosome-associated regulators of the G2/M checkpoint as targets for cancer therapy. Mol Cancer. (2009) 8:8. doi: 10.1186/1476-4598-8-8

12. Wang WG, Sun WX, Gao BS, Lian X, Zhou HL. Cell cycle arrest as a therapeutic target of acute kidney injury. Curr Protein Pept Sci. (2017) 18:1224-31. doi: 10.2174/1389203717666160915162238

13. Park MT, Lee SJ. Cell cycle and cancer. J Biochem Mol Biol. (2003) 36:60-5. doi: 10.5483/BMBRep.2003.36.1.060

\section{FUNDING}

This research was funded by the National Natural Science Foundation of China (31870338 to QZ, 81872162 to DL), the Shandong Provincial Natural Science Foundation, China (Grant No. ZR2017JL030 to DL), the Key Research and Development Program of Shandong Province of China (2019GSF108214 to QZ), Taishan Scholars Construction Engineering of Shandong Province (to DL), the Yantai High-End Talent Introduction Plan Double Hundred (to DL), the Dominant Disciplines' Talent Team Development Scheme of Higher Education of Shandong Province (to DL), and the Introduction and Cultivation Project for Young Creative Talents of Higher Education of Shandong Province (to ML).

14. Roberts JM, Koff A, Polyak K, Firpo E, Collins S, Ohtsubo M, et al. Cyclins, Cdks, and cyclin kinase inhibitors. Cold Spring Harb Symp Quant Biol. (1994) 59:31-8. doi: 10.1101/SQB.1994.059.01.006

15. Bertoli C, Skotheim JM, De Bruin RA. Control of cell cycle transcription during G1 and S phases. Nat Rev Mol Cell Biol. (2013) 14:518-28. doi: $10.1038 / \mathrm{nrm} 3629$

16. Chen RH, Waters JC, Salmon ED, Murray AW. Association of spindle assembly checkpoint component XMAD2 with unattached kinetochores. Science. (1996) 274:242-6. doi: 10.1126/science.274.5285.242

17. Bartek J, Lukas J. Mammalian G1- and S-phase checkpoints in response to DNA damage. Curr Opin Cell Biol. (2001) 13:738-47. doi: 10.1016/S0955-0674(00)00280-5

18. Kerr JF, Wyllie AH, Currie AR. Apoptosis: a basic biological phenomenon with wide-ranging implications in tissue kinetics. Br J Cancer. (1972) 26:23957. doi: 10.1038/bjc.1972.33

19. Cohen GM. Caspases: the executioners of apoptosis. Biochem J. (1997) 326(Pt 1):1-16. doi: 10.1042/bj3260001

20. Gamen S, Anel A, Pineiro A, Naval J. Caspases are the main executioners of Fas-mediated apoptosis, irrespective of the ceramide signalling pathway. Cell Death Differ. (1998) 5:241-9. doi: 10.1038/sj.cdd.4400344

21. Liao Y, Yang F, Li X, Chen K, Zhou L, Wang Y, et al. The impact of Caspase8 on non-small cell lung cancer brain metastasis in II/III stage patient. Neoplasma. (2015) 9:91-4. doi: 10.4149/neo_2015_043

22. Bratton SB, Macfarlane M, Cain K, Cohen GM. Protein complexes activate distinct caspase cascades in death receptor and stress-induced apoptosis. Exp Cell Res. (2000) 256:27-33. doi: 10.1006/excr.2000.4835

23. Takahashi A. Caspase: executioner and undertaker of apoptosis. Int J Hematol. (1999) 70:226-32.

24. Cecka F, Hornychova H, Melichar B, Ryska A, Jandik P, Mergancova $\mathrm{J}$, et al. Expression of bcl-2 in breast cancer: correlation with clinicopathological characteristics and survival. Acta Medica. (2008) 51:107-12. doi: 10.14712/18059694.2017.11

25. Strasser A, Cory S, Adams JM. Deciphering the rules of programmed cell death to improve therapy of cancer and other diseases. EMBO J. (2011) 30:3667-83. doi: 10.1038/emboj.2011.307

Conflict of Interest: The authors declare that the research was conducted in the absence of any commercial or financial relationships that could be construed as a potential conflict of interest.

Copyright (c) $2020 \mathrm{Hu}$, Yang, Liu, Pan, Zhang, Li, Liu, Zheng and Li. This is an open-access article distributed under the terms of the Creative Commons Attribution License (CC BY). The use, distribution or reproduction in other forums is permitted, provided the original author(s) and the copyright owner(s) are credited and that the original publication in this journal is cited, in accordance with accepted academic practice. No use, distribution or reproduction is permitted which does not comply with these terms. 